\title{
No vertical scar breast reduction: A good alternative to the T-scar inferior pedicle breast reduction
}

\author{
Donald H Lalonde BSc MSc MD FRCSC \\ Saint John Regional Hospital, Dalhousie University, Saint John, New Brunswick
}

\begin{abstract}
DH Lalonde. No vertical scar breast reduction: A good alternative to the $T$-scar inferior pedicle breast reduction. Can J Plast Surg 2000;8(1):36-40.

Techniques of the no vertical scar breast reduction, as used in more than 65 patients for over three years, are detailed. This technique is basically the same as the standard inferior pedical T-scar technique, except that the verticle scar is eliminated. Refinements of the technique include avoiding the 'armpit' breast; creating tension-free periareolar suturing with a small areolar hole; knowing how to perform the technique when there is only $3 \mathrm{~cm}$ of skin between the areola and the new areola position; and applying the same technique to mastopexy.
\end{abstract}

Key Words: Breast; Mammoplasty; Reduction; Scar

Réduction mammaire à cicatrice non verticale : une bonne solution de remplacement à la réduction mammaire à cicatrice en $\mathbf{T}$ par pédicule inférieur

RÉSUMÉ : La technique de réduction mammaire à cicatrice non verticale, telle qu'elle a été utilisée chez plus de 65 patientes depuis ces trois dernières années, est détaillée. Cette technique est sensiblement la même que la technique standard avec cicatrice en $\mathrm{T}$ par pédicule inférieur excepté que la cicatrice verticale est éliminée. Les améliorations de cette technique permettent d'éviter le sein « aisselle », de réaliser une suture sans tension autour de l'aréole avec un petit orifice aréolaire ; de pouvoir réaliser cette intervention lorsqu'il y a seulement $3 \mathrm{~cm}$ de peau entre l'aréole et la nouvelle position de l'aréole ; et d'appliquer la même technique à la mastopexie.

A lthough the vertical scar breast reduction technique championed by Lejour is gaining increasing popularity, most surgeons still use the Wise pattern inferior pedicle with the inverted T-scar for their breast reductions.

The 'no vertical scar' technique eliminates the vertical stem of the inverted T-scar. There have been a few reports of this technique in the literature (1-5), but it has failed to gain wide acceptance.

I used the inferior pedicle T-scar for the first 12 years of my practice. For the past three years, I have replaced the in-

This article is the winner of the 1999 Canadian Journal of Plastic Surgery Prize

Correspondence: Dr D Lalonde, 705 Millidge Avenue, Saint John, New Brunswick E2K 2N7. Telephone 506-648-7950,

fax 506-52-8042,e-mail huzil@health.nb.ca verted T-scar Wise pattern with the no vertical scar technique for most breast reductions. The purpose of this article is to share refinements in the technique used in over 60 cases.

\section{SURGICAL TECHNIQUE}

The only difference between the no vertical scar breast reduction and the inferior pedicle inverted T-scar Wise pattern breast reduction is that the quadrilateral piece of skin and fat beneath the areola is preserved instead of discarded (Figures 1-3).

Perhaps the most appealing feature of this technique for those who use a T-scar is that the no vertical scar technique is totally reversible (Figure 3). After the reduction, before the final skin sewing, the surgeon can still convert the procedure to an inverted $\mathrm{T}$-scar Wise pattern by simply cutting the skin 


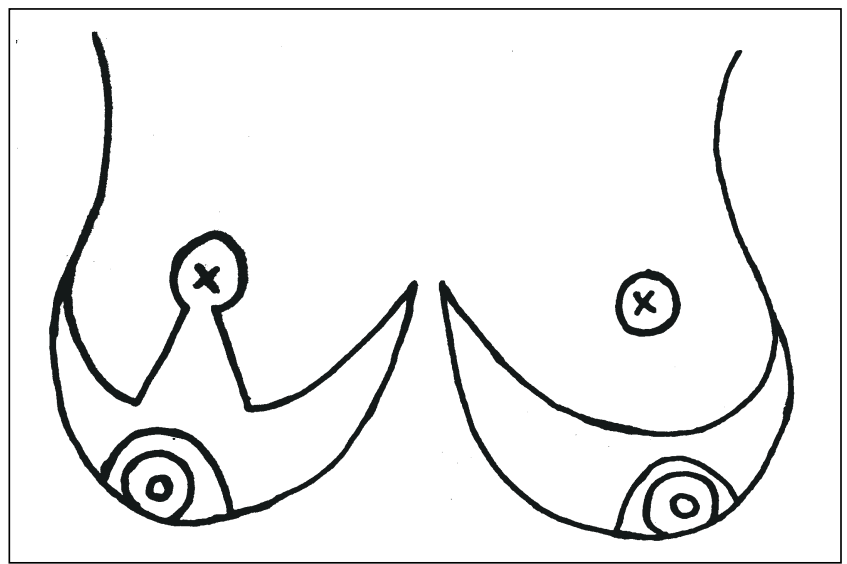

Figure 1) The quadrilateral skin and fat below the new areola site $(x)$ is discarded in the inverted T-scar Wise pattern (left breast) but is not discarded in the no vertical scar technique (right breast) (see Figure 2)

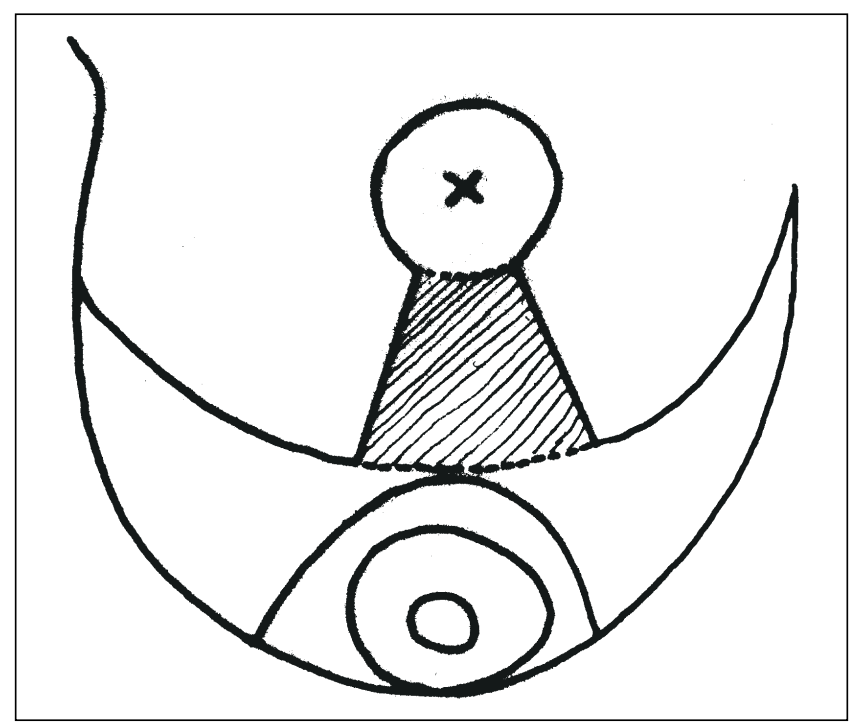

Figure 2) The shaded quadrilateral skin and fat between the new areola site $(x)$ and the old areola is preserved in the no vertical scar technique. As in the Wise pattern, the height of this piece of skin is $5 \mathrm{~cm}$ in most breasts and up to $6 \mathrm{~cm}$ in very large breasts

and fat as shown in Figure 3. Surgeons who are used to the $\mathrm{T}$-scar breast reduction can easily abandon the no vertical scar technique for their usual vertical scar at the end of the procedure if they desire.

In the no vertical scar technique, the blood supply to the areola is based on the standard inferior/glandular pedicle. The pedicle is dissected and de-epithelialized in the same way as the usual inferior pedicle breast reduction.

The breast skin flap is kept 1.5 to $2 \mathrm{~cm}$ thick to preserve the superficial fascial blood supply (Figure 4). The flap is dissected all the way to the loose areolar tissue of the chest wall. This loose areolar tissue is preserved because it is rich in nerves and vasculature. The areolar hole is cut out of the breast skin/fat flap with its inferior border 5 to $6 \mathrm{~cm}$ from the inferior edge of the flap. The new breast is made of two flaps; the breast skin/fat flap and the breast mound flap (Figure 5).

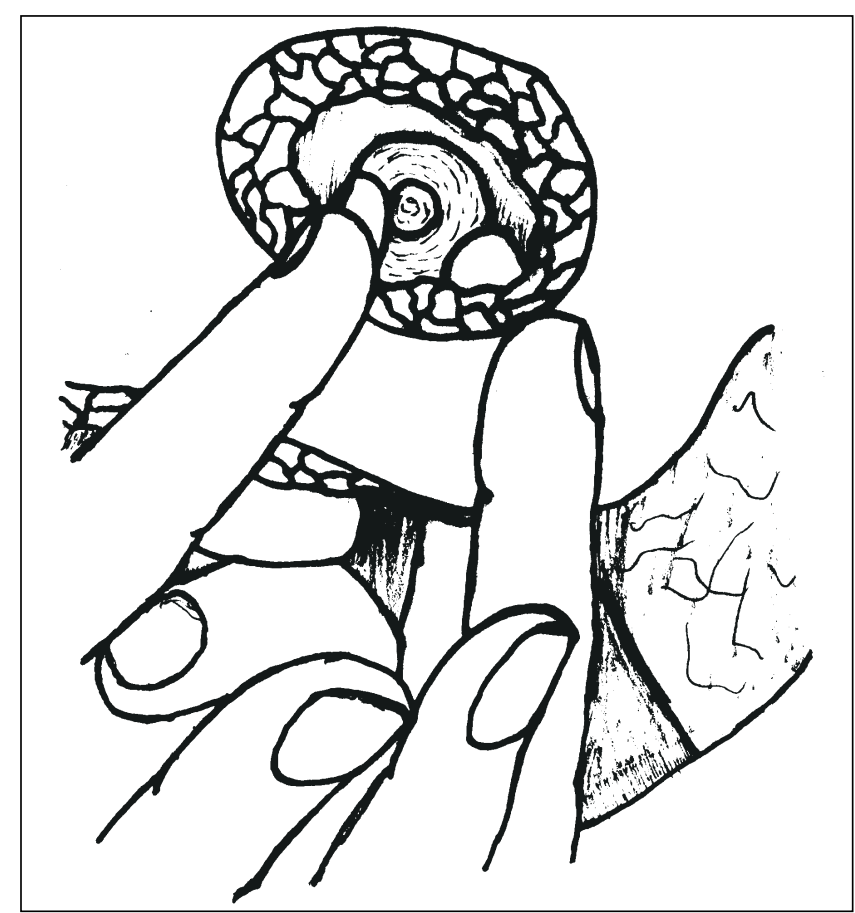

Figure 3) Reversibility of the no vertical scar technique. At the end of the procedure, the surgeon can cut in the area shown by the fingers to convert the no vertical scar pedicle to a standard inverted T-scar Wise pattern

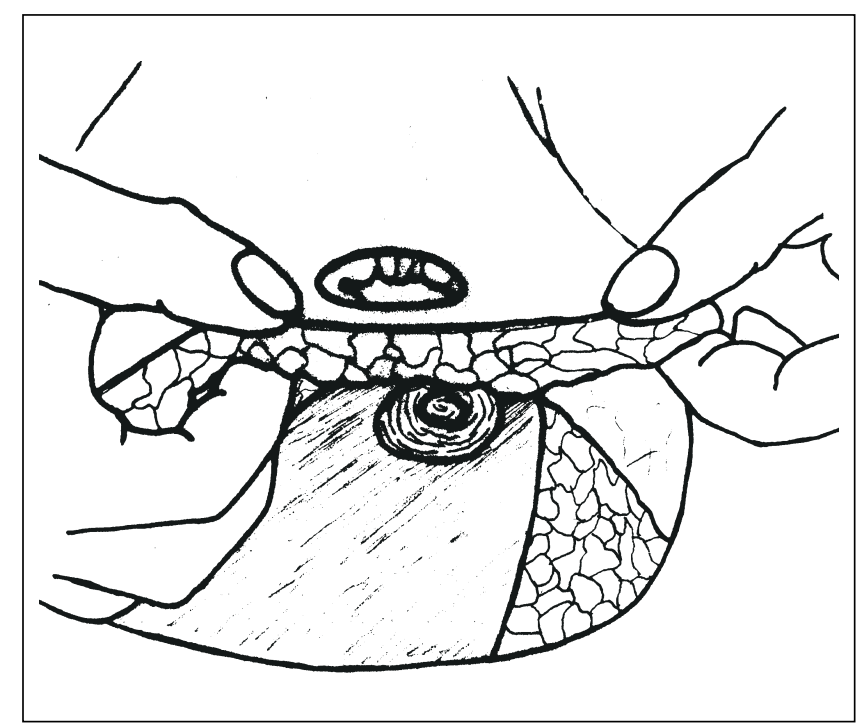

Figure 4) The skin and fat flap is kept 1.5 to $2 \mathrm{~cm}$ thick from below the new areola hole all the way to the loose areolar tissue of the chest wall to preserve the superficial fascial blood supply

The areolar hole is cut small $(2.5 \mathrm{~cm}$ diameter measured sitting) so there is very little tension on the areolar skin suture line and, therefore, a better resulting scar around the areola (4.0 cm diameter measured sitting) (Figures 6,7).

The inferior pedicle dermis is tacked medially to the chest wall with one 3-0 absorbable suture (Figure 8 ) to keep the pedicle from sliding laterally. This improves cleavage and helps to prevent lateral breast bulge because the lateral skin 


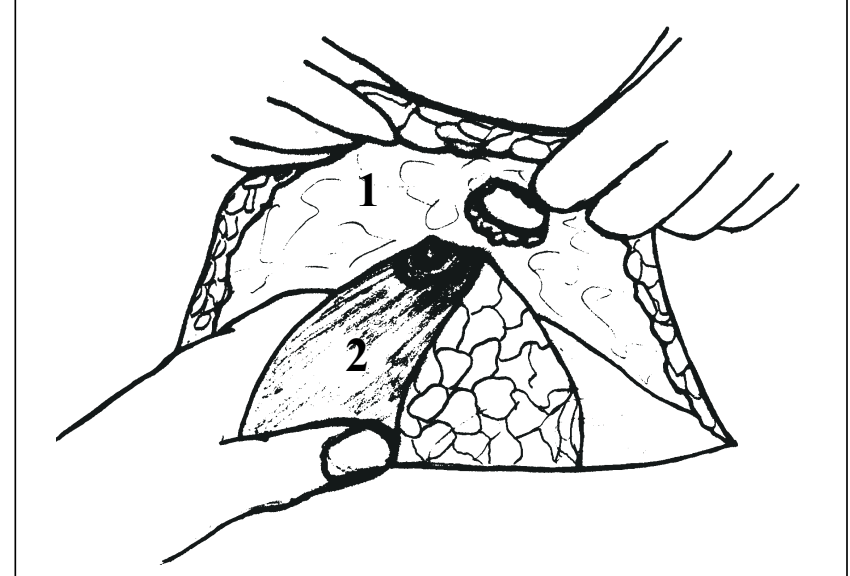

Figure 5) The new breast is made of two flaps -1 the 1.5 to $2 \mathrm{~cm}$ skin and fat flap all the way to the loose areolar tissue of the chest wall, and $\mathbf{2}$ the breast mound (inferior pedicle) flap

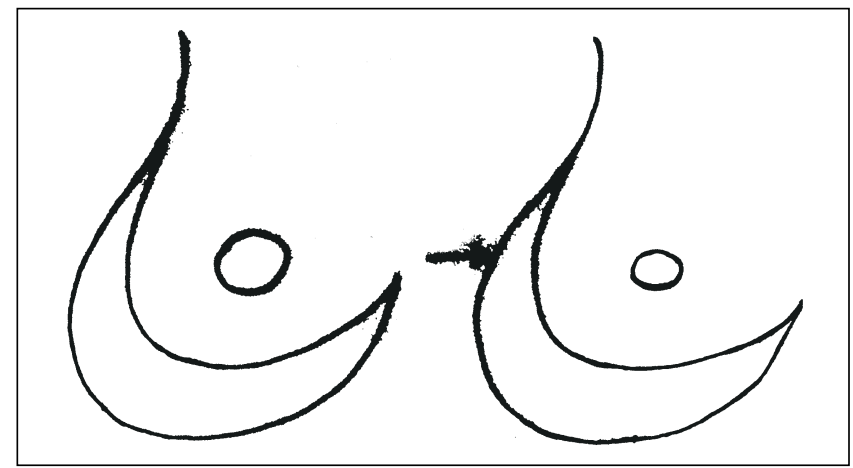

Figure 6) Make the areola hole smaller. The areola hole is measured on the sitting patient at a diameter of $2.5 \mathrm{~cm}$ so that there will be little or no tension at the areolar skin suture line for a better scar (see Figure 12). The areola is measured at a standard $4.0 \mathrm{~cm}$ diameter

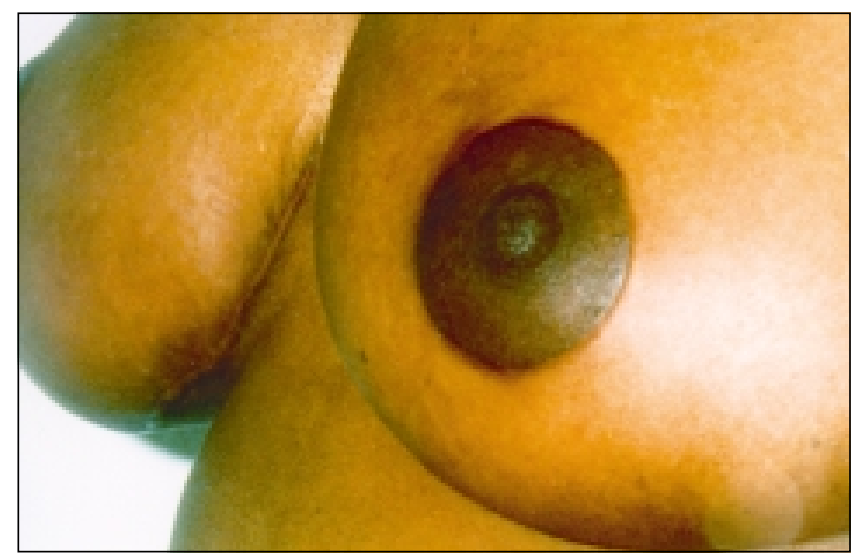

Figure 7) Areolar scar resulting from the technique shown in Figure 6. The inframammary scar is mostly hidden with the patient vertical. This same patient is shown in Figure 10

and fat flap can collapse and scar to the chest wall. Lateral breast bulge is also preserved by removing all of the lateral breast from the loose areolar chest wall tissue to the 1.5 to $2 \mathrm{~cm}$ thick lateral skin and fat flap laterally.

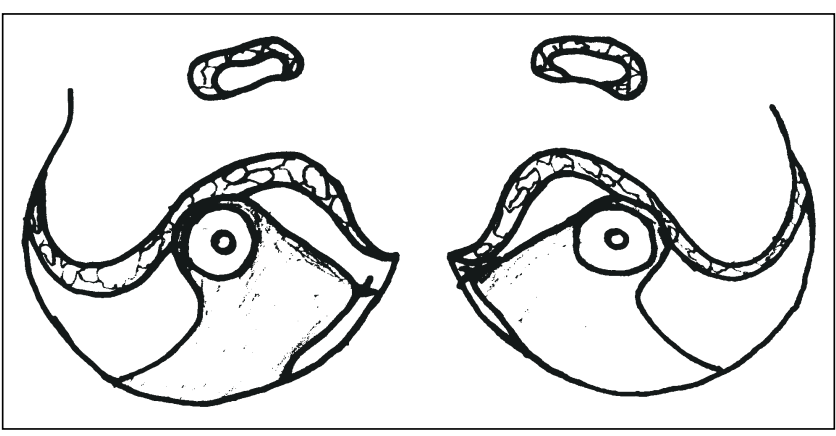

Figure 8) The inferior pedicle dermis is tacked medially with one 3-0 absorbable suture so the lateral skin and fat flap can collapse and scar to the lateral chest wall without the inferior pedicle migrating laterally. This keeps medial cleavage and helps prevent lateral breast bulge.

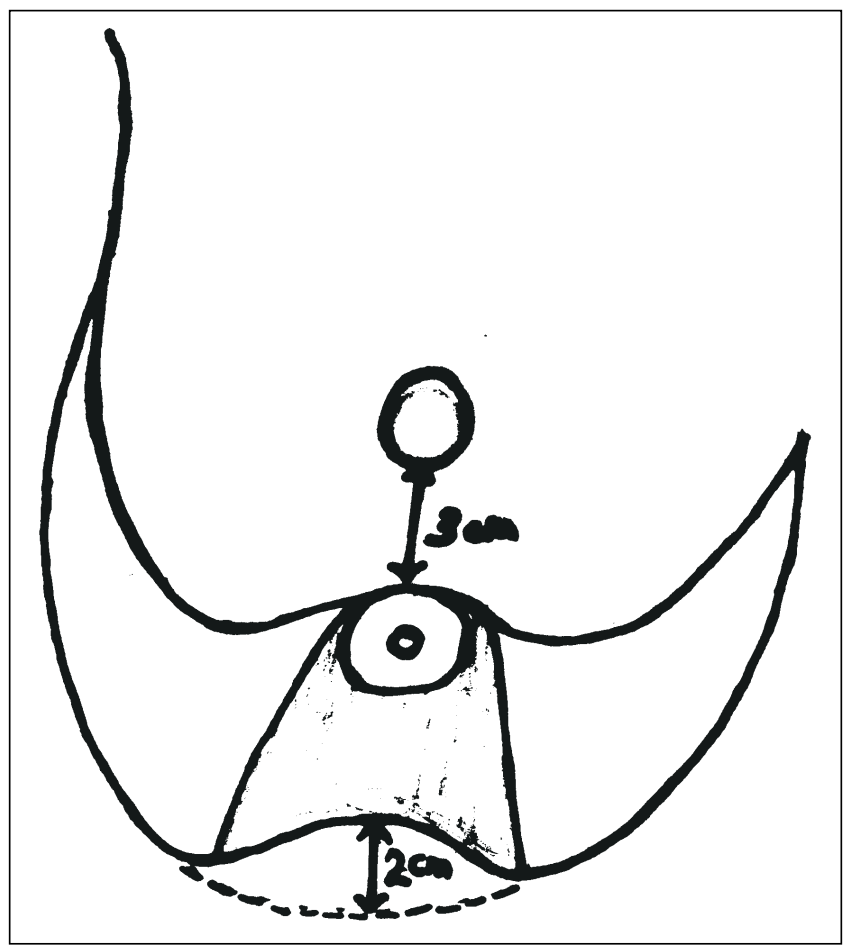

Figure 9) Up to $2 \mathrm{~cm}$ of skin can be borrowed from the inferior pedicle by not de-epithelializing it. This allows the no vertical scar technique to be used when there is only $3 \mathrm{~cm}$ of skin between the new areola hole and the areola (see clinical case Figures 7,10)

There should be between 5 and $6 \mathrm{~cm}$ of skin between the inferior edge of the new areola hole and the areola. I have used up to $2 \mathrm{~cm}$ of skin not de-epithelialized on the inferior pedicle to make up for only $3 \mathrm{~cm}$ of skin between the new areola hole and the areola (Figure 9). The resulting higher horizontal scar is still mostly hidden by the breast mound when the patient is sitting or standing (Figures 7,10).

The horizontal scar has more skin on the breast flap side than on the chest wall side; therefore, gathering is required to even out the puckering, as is done with the Binelli mastopexy. Running intradermal bites of $1 \mathrm{~cm}$ long are taken on the breast flap side, father apart than the $0.7 \mathrm{~cm}$ long bites taken closer together on the chest wall side (Figure 11). If the 


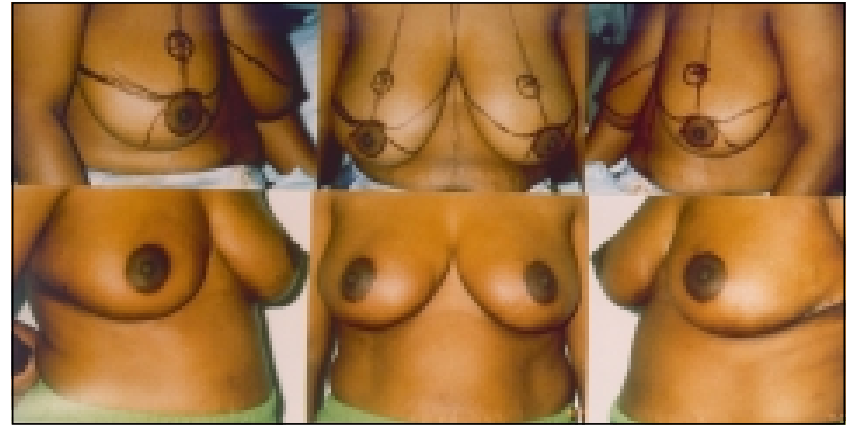

Figure 10) Top Preoperative breast with marking. Only $4.0 \mathrm{~cm}$ of skin was available between the areola and its new location Two centimeters was left unde-epithelialized on the inferior pedicle to make a total of 6.0 $\mathrm{cm}$ of skin between the areola and the inframammary fold using the technique shown in Figure 9. Bottom Three months after operation. This same patient is shown in Figure 7

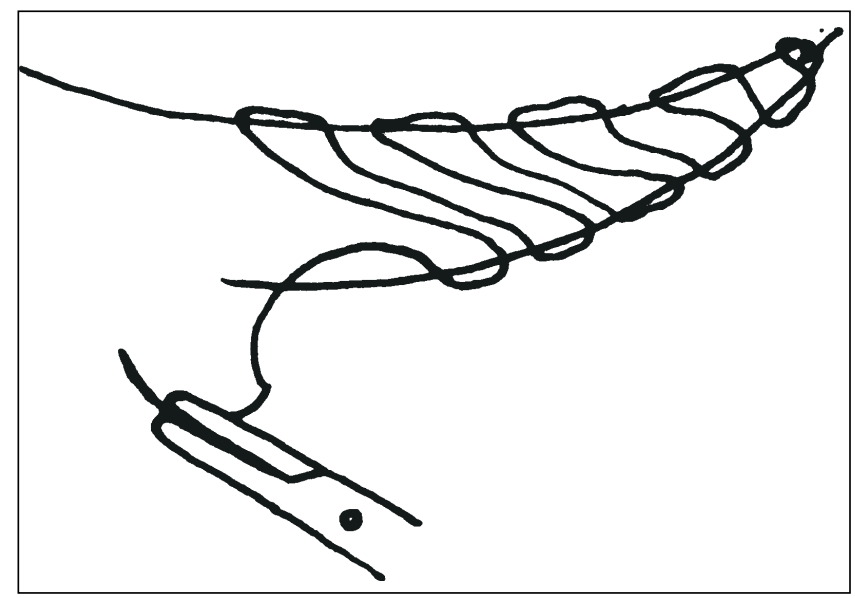

Figure 11) Gathering is required because there is more breast skin than chest wall skin. Longer bites of breast skin are taken farther apart than the shorter bites of chest wall skin for even gathering of the whole horizontal scar

gathering is performed evenly, the wrinkling will settle in one to four months as it does with the Binelli mastopexy (Figure 12).

I have also used the no vertical scar technique for pure mastopexy where all excess skin is de-epithelialized and no skin or breast is removed (Figure 13).

\section{DISCUSSION}

Deletion of the vertical scar adds a significant plus to the esthetic result of the standard inferior pedicle T-scar breast reduction. Patients prefer fewer scars on their breasts, and patient preference of this technique has been high in my practice. The vertical scar is more noticeable than the horizontal scar in the sitting or standing position, which is how most patients see their own body in a mirror.

\section{Why is the vertical scar used in the Wise pattern?}

Skin length equalization. With the Wise pattern, no gathering is required on the horizontal scar because breast skin flap length is equal to chest wall skin length. However, the Wise pattern was developed before

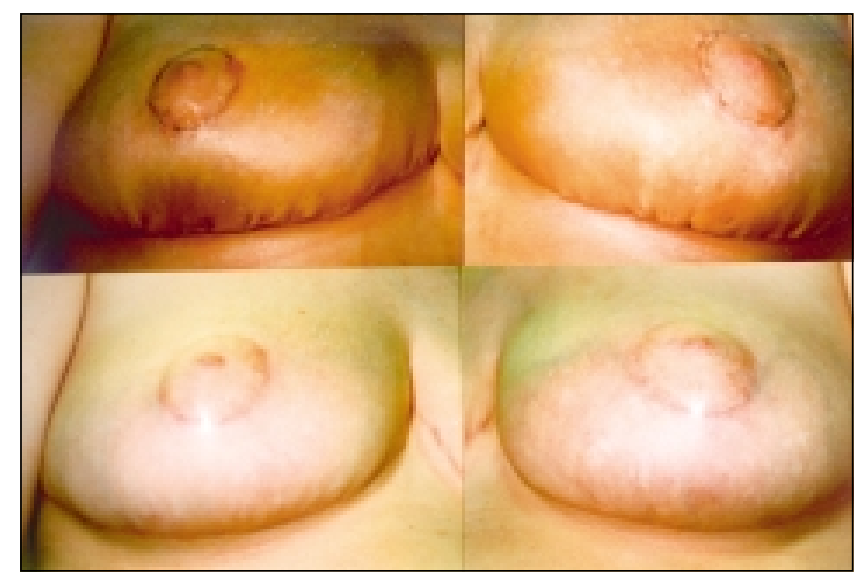

Figure 12) Inframammary scar three weeks (top) and three months (bottom) after operation to show smoothing of gathered wrinkles, which is typical of the technique

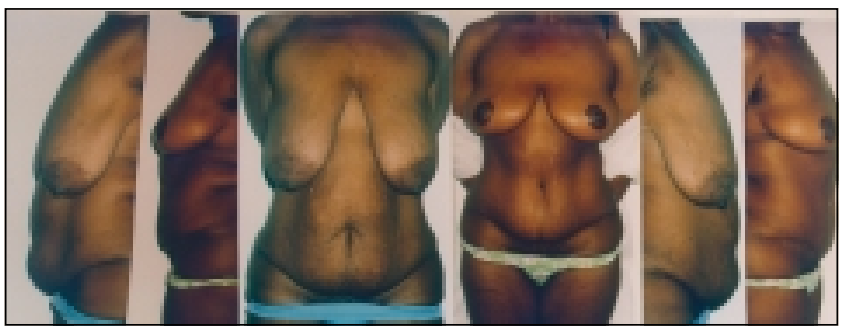

Figure 13) Views of a patient who underwent abdominoplasty and no vertical scar mastopexy before $(\mathbf{A}, \mathbf{C}, \mathbf{E})$ and after $(\mathbf{B}, \mathbf{D}, \mathbf{F})$ surgery. No skin or breast was removed. Lower skin was de-epithelialized

Binelli popularized the concept that minor puckering in gathered skin does not persist. Now that this concept is understood, the vertical scar of the Wise pattern is no longer necessary to equalize the skin length (Figure 12).

Breast shape improvement. Does removal of the quadrilateral skin and fat shown in Figure 2 improve the shape of the breast? This is debatable. Some have criticized the shape of the no vertical scar breast reduction (6). However, others (7) have found that the technique provides excellent results in volume and form. It is my impression that the breast shape is not significantly worse or better in my three years of using no vertical scar versus 12 years of using inverted T-scar Wise pattern breast reduction (Figure 14).

\section{Advantages of the no vertical scar technique}

It is reversible. If the surgeon who tries it for the first time does not like it, he or she can cut out the cross-hatched quadrilateral piece of skin/fat under the areola as shown in Figures 2 and 3 and convert the case to a standard Wise pattern inverted T-scar.

It eliminates the vertical scar of the standard Wise pattern.

The surgical technique is almost identical to the inferior pedicle Wise pattern breast reduction. Surgeons familiar with that technique will find the transition easy. 


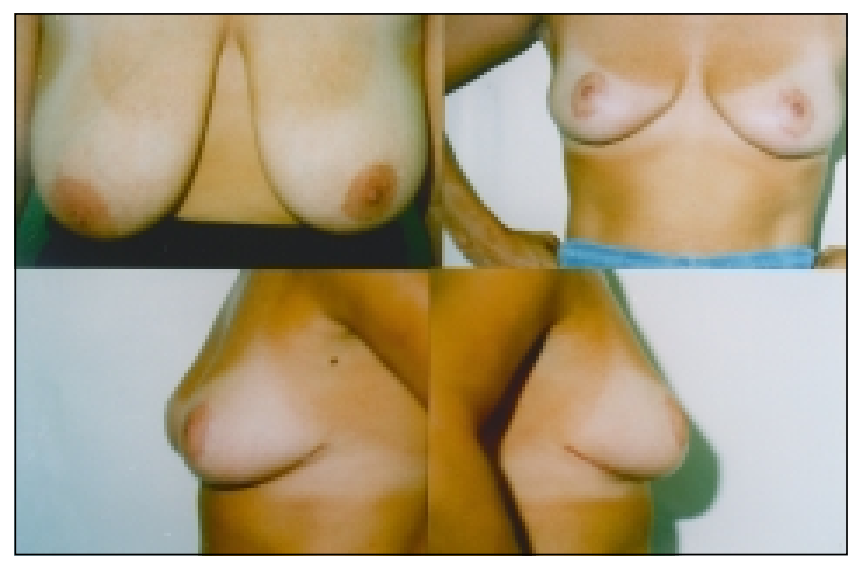

Figure 14) Top left Preoperative breast. Top right, bottom left, bottom right Good breast shape six months after no vertical scar breast reduction surgery

It eliminates the intraoperative cutting and sewing time required for the vertical scar.

In my experience, eliminating the vertical scar does not appear to affect the breast shape adversely.

A small areolar hole makes a better periareolar scar.

\section{Disadvantages of the no vertical scar technique}

Gathering is required in the horizontal inframammary incision to prevent puckering because the breast skin flap length is longer than the chest wall skin flap length. The surgeon must have faith that the fine wrinkling will settle, as it does in the Binelli mastopexy.

The technique cannot be used if there is less than $3 \mathrm{~cm}$ between the areola and the new areola hole (Figure 9).

Yousef and Larson (3) and Yousef et al (4) believed that the no vertical scar technique could lead to a lateral breast bulge and attempted to solve the problem by doing most of the skin gathering below the areola. The lateral bulge is addressed in this series by removing all of the lateral breast between the loose areolar tissue of the chest wall and the 1.5 to
$2 \mathrm{~cm} \mathrm{skin/fat} \mathrm{breast} \mathrm{flap} \mathrm{and} \mathrm{by} \mathrm{tacking} \mathrm{the} \mathrm{inferior} \mathrm{breast} \mathrm{pe-}$ dicle dermis medially to prevent the pedicle from sliding laterally before adhesions develop between the lateral breast skin/fat flap and the lateral chest wall.

It is important to leave a 1.5 to $2 \mathrm{~cm}$ thickness of skin/fat tissue on the breast skin flap to preserve the superficial fascial blood supply. In the first few cases of this series, small amounts of skin were lost below the areola in two patients, because the superficial fascia and its blood supply were removed and the flap was thinned out too aggressively at less than 1.5 to $2 \mathrm{~cm}$ thickness.

Cutting a $2.5 \mathrm{~cm}$ diameter areola hole in the breast flap (measured preoperatively with the patient sitting) and placing a $4 \mathrm{~cm}$ measured areola into that hole makes for a completely tension free suture line around the areola. It is reasonable that no tension will lead to a better areolar scar.

In summary, I believe that the no vertical scar technique is a good alternative to the inverted T-scar in most patients who have $3 \mathrm{~cm}$ of skin or more between the new areola hole and the areola.

ACKNOWLEDGMENTS: The author thanks Jan Lalonde and Claire Milne for their help in the preparation of this manuscript.

\section{REFERENCES}

1. Ribiero L. A new technique for reduction mammaplasty. Plast Reconstr Surg 1975;55:330-4

2. Thomas WO, Moline S, Harris CN. Design-enhanced breast reduction: an approach for very large, very ptotic breasts without a vertical incision. Ann Plast Surg 1998;40:229-34.

3. Yousef NJ, Larson DL. The apron technique of reduction mammaplasty: elimination of the vertical scar. Perspect Plast Surg 1994;8:137-44.

4. Yousef NJ, Larson DL, Sanger JR, et al. Elimination of the vertical scar in reduction mammoplasty. Plast Reconstr Surg 1992;89:459-67.

5. Conway H. Mammaplasty: analysis of 110 consecutive cases with end results. Plast Reconstr Surg 1952;10:303-15.

6. Peled IJ. Re: Breast reduction without a vertical scar. Ann Plast Surg 1998;41:451.

7. Bostwick III J. The apron technique of reduction mammaplasty: Editor's perspective. Perspect Plast Surg 1994;8:145-6. 